\title{
Publicaciones impresas
}

\author{
Alejandro Calderón \\ Comunicador Social-Periodista \\ Facultad de Ciencias de la Comunicación - UNIMINUTO \\ extrabigbag@yahoo.com
}

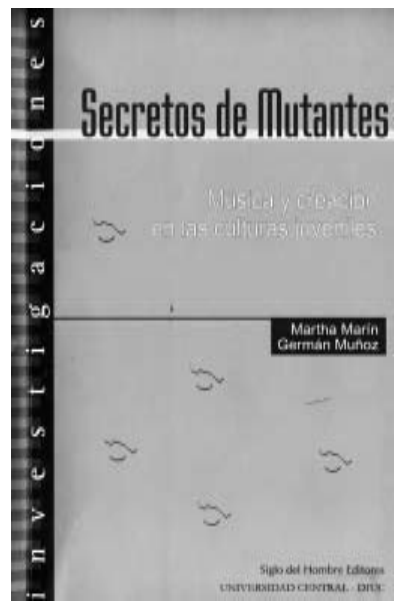

"Secretos de Mutantes.

Música y Creación en las Culturas Juveniles".

Autor: Martha Marín y Germán Muñoz.

Siglo del Hombre Editores.

Universidad Central.

Departamento de Investigaciones de la Universidad Central DIUC.

La temática de las culturas juveniles en el ámbito de las ciudades, es recurrente en las investigaciones sociales y permiten evidenciar procesos de cambio y transformación no solo generacional sino en general, de los grupos humanos.

"Secretos de Mutantes", es un análisis investigativo de los grupos juveniles y su dinámica urbana, desde el escenario de la música, como sistema cohesor de visiones y representaciones del mundo.

Este trabajo es el resultado de las indagaciones de los investigadores, 
sobre los imaginarios construidos o co-construidos, desde la realidad del cine y que, tras la movilidad propia de las investigaciones sociales, desemboca en un estudio donde la música y las agrupaciones juveniles como los skinheads, metaleros, punkeros, REAS y otros, se convierten en actores protagónicos del cambio en las ciudades.

Así mismo, como trabajo de investigación, este libro incluye entrevistas y metodologías utilizadas para acercarse a las visiones y modos de representación, de los grupos urbanos.

Es posible entonces discernir en el texto, cómo la música y otros medios de expresión como los volantes contra las corridas de toros o contra los circos, son mecanismos de divulgación que cohabitan con las formas usuales de expresión del resto de la sociedad; igualmente, deja ver que estos grupos, lejos de ser las llamadas contraculturas, son mas bien, culturas paralelas, que se cruzan y entrecruzan en un espeso ovillo, con la "cultura mayor" de la ciudad, de la cual se alimentan y a la cual, a su vez, alimentarz

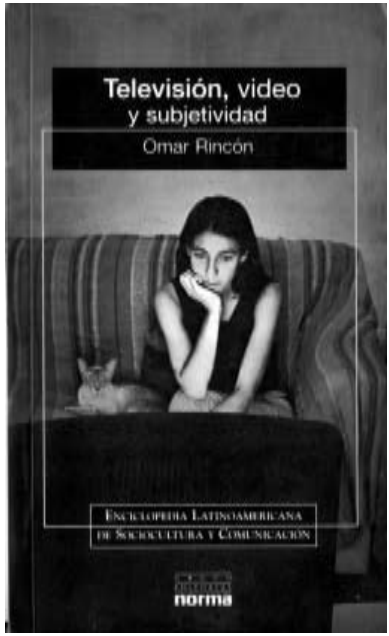

\section{“Televisión, Video y Subjetividad". Autor: Omar Rincón. Enciclopedia Latinoamericana de Sociocultura y Comunicación. Grupo Editorial Norma.}

¿Qué es la televisión: Io técnico, las personas, la programación, los programas o el "efecto" televisión?, es ante todo una construcción compleja que se nutre de las realidades, tanto propias como lejanas y las re-crea dentro de los patrones de un formato televisivo; toma significados y significaciones y los reinterpreta. Asimismo, mezcla modelos de lo social, lo estético, lo cultural y demás y busca la manera de adaptarlos y proyectarlos a un público más o menos homogéneo, que por supuesto, comparte un espacio y un tiempo similares. Pero es claro que no siempre en el "mundo de la televisión", la línea que separa la realidad de la fantasía o de la ficción, es taxativamente clara y cierta; por el contrario, es difusa y se entreteje en planos opuestos y que parecen 
irreconciliables.

Por lo mismo, análisis sobre la televisión hay bastantes y es claro entonces que a partir de ellos, esta es un ente, una industria y hasta un espacio. Pero en el texto "Televisión, Video y Subjetividad" del profesor Omar Rincón, se añade un elemento provocador: la subjetividad, es decir que la televisión es tanto un ente como una industria y un espacio; aunque también es un actor y un sujeto. Y como sujeto, interlocuta a su manera con otros.

Pero además de interlocutar, la televisión construye y deconstruye significados, es capaz de generar simbolizaciones, moviliza y es movilizada, es política; en síntesis, como actor tiene incidencia social más allá de lo meramente estadístico en las tablas de rating o de los comentarios de almuerzo sobre el capítulo de la novela o de la calidad de los contenidos de la parrilla de programas. La televisión "habla" con el televidente, entre ambos "tranzan" negociaciones de cercanía, comprensiones, compañías, importancia del uno hacia el otro, rabias y hasta celos. Se trastocan los sentidos respecto a lo que gusta y lo que no, el televidente puja con la televisión, la televisión ya es otro con quien se cohabita; ambos tejen colectividad y abandonan el espacio cosmopolita de las grandes ciudades comerciales donde nadie se conoce con nadie, para llegar al barrio, la comuna, la cabecera de municipio, en donde todos son protagonistas.

Yesa es una de las propuestas, que la televisión sea capaz de redimensionar su tamaño, funcionalidad y contenidos (ien Colombia, la televisión es oral!, se narran las acciones que se muestran, existe una pobreza importante en cuanto a construir con la imagen y construir diferente de la imagen de sangre - la estética de la violencia - , "ver" de otra manera), pues de sobra se sabe que su poder ha sido descentrado. La emergencia de nuevas televisiones y de nuevas maneras de contar y de penso"saberes y significaciones, son en este momento el acicate para transformar las 